\title{
Other Presenters
}

\section{Oral Presenters}

\author{
Creating Pearls from Chaos \\ Fairland Amos ${ }^{a}$, Ellen Keene ${ }^{\mathrm{b}}$, Lara Estroff ${ }^{\mathrm{b}}$, Elaine DiMasi ${ }^{\mathrm{c}}$, \\ John Spencer Evans ${ }^{\text {a }}$ \\ aLaboratory for Chemical Physics, New York University, New \\ York, N.Y., 'bepartment of Materials Science and Engineering, \\ Cornell University, New York, N.Y., and 'Brookhaven National \\ Laboratories, Ridge, N.Y., USA
}

\section{Hyperglycemia in Type 1 Diabetic Mice Is Associated with Enamel Defects and Acute Pulpitis}

Zhiyong Fan a , Diane Horn ${ }^{\text {a }}$, Kathleen Woodruff ${ }^{\text {, }}$, Mary MacDougall ${ }^{\mathrm{b}}$, Sherry Abboud-Werner ${ }^{\mathrm{a}}$.

aUniversity of Texas Health Science Center, San Antonio, Tex., and

bUniversity of Alabama at Birmingham, Birmingham, Ala., USA

\section{Dental Convergent Evolution; Enamel-Like Molar Tooth Found in a Crayfish Mandible}

S. Bentov $^{\text {a }}$, P. Zaslansky ${ }^{\text {b }}$, A. Al-Sawalmih ${ }^{\text {b }}$, A. Masic ${ }^{\text {b }}$,

B. Aichmayer ${ }^{\text {b }}$, A. Sagi ${ }^{\mathrm{a}}$, A. Berman ${ }^{\mathrm{a}}$

aDepartment of Life Sciences and the National Institute for Biotechnology in the Negev, Ben Gurion University, Beer Sheva, Israel; bMax Planck Institute of Colloids and Interfaces, Potsdam, Germany

Bioactive Multidomain Peptides and Their Application for Dental Tissue Regeneration Katherine R. Regan ${ }^{\text {a, b }}$, Kerstin M. Galler ${ }^{c}$, Jeffrey D. Hartgerink ${ }^{b}$, Rena N. D'Souza a

aDepartment of Biomedical Sciences, Baylor College of Dentistry, Texas A\&M, Dallas, Tex., and ${ }^{\mathrm{b}}$ Departments of Chemistry and Bioengineering, Rice University, Houston, Tex., USA; 'Department of Restorative Dentistry and Periodontology, University of Regensburg, Regensburg, Germany

\author{
Different Modes of Collagen Mineralization \\ Elia Beniash, Atul Deshpande, Pingan Fang, Aparna Raman, \\ Charles Sfeir \\ Oral Biology, University of Pittsburgh, Pittsburgh, Pa., USA
}

\section{Atom Probe Tomography of Buried Organic-Inorganic Interfaces in Biominerals \\ Lyle Gordon, Derk Joester \\ Department of Materials Science and Engineering, Northwestern University, Evanston, III., USA}

\section{Influence of Polymeric Process-Directing Agent on Mineralization of Collagen via the PILP Process}

Taili Thula, Felicia Svedlund, Laurie B. Gower

Department of Materials Science and Engineering, University of Florida, Gainesville, Fla., USA

\section{Remineralization of Partially Demineralized Human Dentin via the Polymer-Induced Liquid-Precursor (PILP) Process \\ Taili Thula-Mata ${ }^{a}$, Anora Burwell ${ }^{\text {b }}$, Laurie B. Gower ${ }^{\text {, }}$ Stefan Habelizt ${ }^{\text {}}$, Grayson Marshall ${ }^{\mathrm{b}}$ \\ ${ }^{a}$ Department of Materials Science and Engineering, University of Florida, Gainesville, Fla., and bepartment of Preventive and Restorative Dental Sciences, University of California, San Francisco, Calif., USA}

\section{An Essential Role for T Lymphocytes in Mesenchymal Stem Cell-Based Tissue Engineering}

Yi Liu, Lei Wang, Takashi Kikuiri, Kentaro Akiyama, Chider Chen, Songtao Shi

Center for Craniofacial Molecular Biology, Herman Ostrow School of Dentistry, University of Southern California, Los Angeles, Calif., USA

Presenting authors are underlined.

\begin{tabular}{ll}
\hline KARGER & ( ) 2011 S. Karger AG, Basel \\
Fax +41 61306 1234-6405/11/1944-0331\$38.00/0 \\
$\begin{array}{l}\text { E-Mail karger@karger.ch } \\
\text { www.karger.com }\end{array}$ & $\begin{array}{l}\text { Accessible online at: } \\
\text { www.karger.com/cto }\end{array}$
\end{tabular}


Heterotopic Ossification - Normal Bone in Abnormal Places

Eileen Shore

University of Pennsylvania School of Medicine, Philadelphia, Pa., USA

Biomaterials-Based Strategies for Mineralized Tissue Regeneration

Molly Stevens

Imperial College, London, UK

\section{Poster Presenters}

Accelerated Growth Plate Mineralization and Foreshortened Proximal Limb Bones in Mice Lacking Fetuin-A/ $\alpha 2$-HS Glycoprotein

Jong Seto ${ }^{\text {a }}$, Thorsten Schinke ${ }^{\text {b }}$, Himadri S. Gupta ${ }^{\text {a }}$, Stefanie Krauss a, J.W.C. Dunlop ${ }^{\text {a }}$, Michael Kerschnitzki ${ }^{\text {a }}$, Admir Masic a, Paul Zaslansky a, Peter Boesecke ${ }^{c}$, Philip Catala ${ }^{b}$, Bjorn Busse $^{b}$, Cora Schäfer ${ }^{d}$, Peter Fratzl $^{a}$, Wilhelm Jahnen-Dechent ${ }^{\mathrm{d}}$

aDepartment of Biomaterials, Max Planck Institute of Colloids and Interfaces, Potsdam, and ${ }^{\mathrm{b}}$ Center for Biomechanics, University Clinics Eppendorf, Hamburg, Germany; 'Beamline ID2, European Synchrotron Radiation Facility, Grenoble, France; ${ }^{\mathrm{d} B i o i n t e r f a c e}$ Laboratory, RWTH Aachen University, Aachen, Germany

Spatial Control of Mineralization at the Periodontal Ligament-Cementum Junction

Eli D. Sone ${ }^{\mathrm{a}-\mathrm{c}}$, Bryan D. Quan c, Janice Song b, c, B. Ganss ${ }^{\text {a }}$ ${ }^{\mathrm{a}}$ Faculty of Dentistry, ${ }^{\mathrm{b}}$ Department of Materials Science and Engineering, and "Institute of Biomaterials and Biomedical Engineering, University of Toronto, Toronto, Ont., Canada

Sphingomyelin Phosphodiesterase 3: A Novel Regulator of Skeletal Development

Monzur Murshed ${ }^{\mathrm{a}, \mathrm{b}}$, Zohreh Khavandgar ${ }^{\mathrm{a}}$, Marc D. McKee ${ }^{\mathrm{b}, \mathrm{c}}$

${ }^{\mathrm{a} D e p a r t m e n t}$ of Medicine, ${ }^{\mathrm{b}}$ Faculty of Dentistry, and

'Department of Anatomy and Cell Biology, McGill University, Montreal, Que., Canada

Effects of Hypothyroidism on the Proximal Femoral Physis in Miniature Swine

J. Tank ${ }^{\mathrm{a}}$, D. Weiner ${ }^{\mathrm{b}}, \underline{\text { R. Jacquet }}^{\mathrm{c}}$, M. Morscher ${ }^{\mathrm{b}}$, D. Childs ${ }^{\mathrm{c}}$,

T. Ritzman ${ }^{\mathrm{b}}$, W. Horne ${ }^{\mathrm{c}}$, E. Lowder ${ }^{\mathrm{C}}$, W. Landis ${ }^{\mathrm{c}}$

aSumma Health System and 'b Akron Children's Hospital, Akron, Ohio, and 'Northeastern Ohio Universities Colleges of Medicine and Pharmacy, Rootstown, Ohio, USA
Estrogen Receptor $\alpha$ Stimulates Bone Sialoprotein (BSP) Gene Transcription

Hideki Takai $^{\text {a, b }}$, Youhei Nakayama a, b, Shouta Araki ${ }^{\text {, }}$

Masaru Mezawa ${ }^{\text {a, b }}$, Yorimasa Ogata ${ }^{\text {a, b }}$

a Department of Periodontology and ${ }^{b}$ Research Institute of Oral Science, Nihon University School of Dentistry at Matsudo, Matsudo, Japan

Proteolytic Processing of Dentin

Sialophosphoprotein (DSPP) Were Blocked by Substitutions of Amino Acid Residues at Cleavage Sites

Qinglin Zhu, Yao Sun, Yongbo Lu, Xiaofang Wang, Monica Prasad, Albert Yamoah, Jian Q. Feng, Chunlin Qin

Baylor College of Dentistry, Department of Biomedical Sciences, Dallas, Tex., USA

The Expression of FAM20C (DMP4) in the Tooth and Skeleton Indicates a Unique Role of This Protein in Odontogenesis and Osteogenesis

Xiaofang Wang ${ }^{a}$, Yixia Xie ${ }^{a}$, Janjun $\mathrm{Hao}^{\mathrm{b}}$, Brianda Hernandez ${ }^{\mathrm{a}}$, Yao Sun a , Albert K. Yamoah a , Monica Prasad ${ }^{a}$, Qinglin Zhu ${ }^{a}$, Jian Q. Feng ${ }^{\text {a }}$, Chunlin Qin ${ }^{\text {a }}$

aBaylor College of Dentistry, Department of Biomedical Sciences, Dallas, Tex., and ${ }^{b}$ University of Illinois at Chicago College of Dentistry, Chicago, III., USA

Detection of Small Integrin-Binding Ligand, N-Linked Glycoprotein (SIBLING) Family Members in the Rat Brain

Yao Sun, Monica Prasad, Albert Yamoah, Jian Q. Feng, Chunlin Qin Baylor College of Dentistry, Department of Biomedical Science, Dallas, Tex., USA

Processing of Osteogenic/Dentinogenic Proteins by Three BMP1/Tolloid Metalloproteinase Isoforms

Zofia von Marschall, Larry W. Fisher

Craniofacial and Skeletal Diseases Branch, NIDCR, NIH, DHHS, Bethesda, Md., USA

Use of New Probes for in situ Hybridization on Mineralized Tissues Based on Locked Nucleic Acids (LNAs)

Dominique Hotton a , Alba Bolaňos a, b , Frédéric Lézot ${ }^{\mathrm{a}}$, Didier Ferbus ${ }^{\text {a }}$, Ariane Berdal ${ }^{\text {a }}$

aLaboratory of Molecular Oral Physiopathology, Inserm UMRS 872, Universities Paris 5, 6 and 7, Paris, France; bPharmacology, Dentistry School, Carabobo University, Valencia, Venezuela 
Amelogenin and Ameloblastin Expression in Non-Mineralized Tissues of Adult Mice

Jaime Jacques, Dominique Hotton, Ariane Berdal, Stéphane Petit Laboratory of Molecular Oral Physiopathology, Inserm UMRS 872, Universities Paris 5, 6 and 7, Paris, France

\section{Effect of Systemic Calcium on Tooth Mineralization} in Vitamin D Receptor Deficient Mice

Xueming Zhang, Firoz Rahemtulla, Huw F. Thomas

University of Alabama at Birmingham, School of Dentistry, Birmingham, Ala., USA

\section{Effects of FGF2 on Odontoblasts Differentiation and Expression of Col1a1-GFP in Primary Dental Pulp Cultures}

Karen Sagomonyants, Anamaria Balic, Aleksandr Makeyev, Mina Mina

School of Dental Medicine, University of Connecticut Health Center, Farmington, Conn., USA

Chemically Released Endogenous Growth Factors Influence Cell Behaviour in an ex vivo Mandible Model

Emma L. Smith ${ }^{\text {a }}$, Matthew Locke ${ }^{\text {a }}$, Rachel J. Waddinogton ${ }^{\text {b }}$ Alastair J. Sloan ${ }^{\text {b }}$

aTissue Engineering and Reparative Dentistry, School of Dentistry, and ${ }^{b}$ Cardiff Institute for Tissue Engineering and Repair, School of Dentistry, Cardiff University, Cardiff, UK

\section{Dentin Matrix Protein 1 (DMP1) Signals via Cell Surface Integrin}

Charles Sfeir $^{\mathrm{a}, \mathrm{b}}$, Elia Beniash ${ }^{\mathrm{a}, \mathrm{b}}$, Hong Wu ${ }^{\mathrm{a}}$, Atul Deshpande $^{\mathrm{a}}$, Pang-Ning Teng ${ }^{\mathrm{a}}$ b , Jinhua $\mathrm{Li}^{\mathrm{a}}$, Shinsuke Onishi ${ }^{\mathrm{a}}$

aDepartment of Oral Biology, Center for Craniofacial

Regeneration, Dental Medicine and bepartment of

Bioengineering, University of Pittsburgh, Pittsburgh, Pa., USA

Differences in Mineral Size and Orientation between Embryonal and Postnatal Bone Tissue in Mice

C. Lange $^{\text {a, d }}$, C. Li ${ }^{\text {a }}$, I. Manjubala ${ }^{\text {a }}$, W. Wagermaier ${ }^{\text {a }}$, J. Kühnisch ${ }^{\text {b }}$, M. Kolanczyk c, S. Mundlos b, c, P. Fratzl ${ }^{\text {a }}$

${ }^{a}$ Max Planck Institute of Colloids and Interfaces, Department of Biomaterials, Potsdam, ${ }^{b}$ Charité, Institute for Medical Genetics, 'Max Planck Institute of Molecular Genetics, Research Group Mundlos, and ${ }^{\mathrm{d} B e r l i n-B r a n d e n b u r g}$ School for Regenerative Therapies BSRT, Berlin, Germany
Growth Factor-Binding to Self-Assembling Peptide Hydrogels for Dental Tissue Regeneration

Kerstin M. Galler ${ }^{\text {a }}$ Katherine R. Regan ${ }^{\text {b }}$, Gottfried Schmalz ${ }^{\mathrm{a}}$, Jeffrey D. Hartgerink ${ }^{c}$, Rena N. D'Souza ${ }^{\mathrm{b}}$

aDepartment of Operative Dentistry and Periodontology,

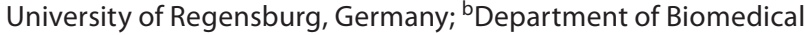
Sciences, Baylor College of Dentistry, Texas A\&M, Dallas, Tex., and 'Departments of Chemistry and Bioengineering, Rice University, Houston, Tex., USA

Tgf- $\beta$ Is Required for Development and Maintenance of the Intervertebral Disc

Megan Cox, Philip Sohn, Rosa Serra

Department of Cell Biology, University of Alabama at Birmingham, Birmingham, Ala., USA

Increased Nano-Scale Roughness Created under Controlled Oxidative Environments Enhances Osteoblast Differentiation

Rolando A. Gittens I ${ }^{\mathrm{a}, \mathrm{b}}$, Taylor McLachlan ${ }^{\mathrm{b}}, \mathrm{Ye} \mathrm{Cai}{ }^{\mathrm{b}}$, Rina Tannenbaum ${ }^{\mathrm{b}}$, Kenneth H. Sandhage ${ }^{\mathrm{b}}$, Simon Bemer ${ }^{\mathrm{c}}$, Zvi Schwartz a , Barbara D. Boyan ${ }^{\text {a }}$

anstitute for Bioengineering and Bioscience, and bSchool of Materials Science and Engineering, Georgia Institute of Technology, Atlanta, Ga., USA; 'Institut Straumann AG, Basel, Switzerland

Role of the Transcriptional Co-Activator CITED1 in Bone and Its Effect on Anabolic Actions of PTH Hila Bahar ${ }^{a}$, Jun Guo a, Dehong Yang a , Rajaram Manoharan ${ }^{\text {b }}$, Toshi Shioda ${ }^{c}$, Mary L. Bouxsein ${ }^{b}$, F. Richard Bringhurst ${ }^{\mathrm{a}}$

aEndocrine Unit, Massachusetts General Hospital, 'b Orthopedic Biomechanics Laboratory, Beth Israel Deaconess Medical Center, and 'Molecular Profiling Laboratory, Massachusetts General Hospital Cancer Center, Boston, Mass., USA

\section{Runx2 Controls FGF Signaling through Twist1 and E12/47 Heterodimers}

Yongbo Lu ${ }^{\mathrm{a}}$, Yucheng $\mathrm{Li}^{\mathrm{a}}$, Adriana Cavender ${ }^{\mathrm{a}}$, Alka Mansukhani ${ }^{\mathrm{b}}$, Rena D'Souza ${ }^{\text {a }}$

${ }^{\mathrm{a} B}$ Baylor College of Dentistry, Dallas, Tex., and ${ }^{\mathrm{b}} \mathrm{New}$ York University, New York, N.Y., USA

Lysyl Hydroxylase 3-Mediated Glycosylation of Type I Collagen Regulates Collagen Matrix Formation and Mineralization

Marnisa Sricholpech, Hideaki Nagaoka, Megumi Yokoyama, Sun Min Lee, Mitsuo Yamauchi

Dental Research Center, School of Dentistry, University of North Carolina at Chapel Hill, Chapel Hill, N.C., USA 
Membrane Estrogen Signaling Leads to Crosstalk among Pathways Associated with Cell Survival and Bone Metastasis of Breast Cancer

R.A.Chaudhri ${ }^{\mathrm{a}}$, $\mathrm{b}$, N. Cuenca $^{\mathrm{b}},{ }^{\mathrm{B}}$ R. Olivares-Navarrete ${ }^{\mathrm{b}}$, B.D. Boyan ${ }^{\mathrm{a}, \mathrm{b}}$, Z. Schwartz $^{\mathrm{b}}$

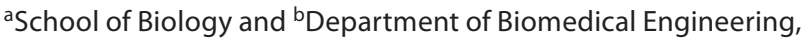
Georgia Institute of Technology, Atlanta, Ga., USA

On the Mineral in Collagen of Human Crown Dentine: a 2D/3D SAXS Study

Anke Märten ${ }^{\mathrm{a}}$, Oskar Paris ${ }^{\mathrm{b}}$, Peter Fratzl ${ }^{\mathrm{a}}$, Paul Zaslansky ${ }^{\mathrm{a}}$

aDepartment of Biomaterials, Max Planck Institute of Colloids and Interfaces, Potsdam, Germany; ${ }^{b}$ Institute of Physics, University of Leoben, Leoben, Austria

Raman Spectroscopic Evidence for Step-Wise Periodic Mineralization in Neonatal Murine Calvarial Suture

John-David P. McElderry ${ }^{\mathrm{a}}$, Guisheng Zhao ${ }^{\mathrm{b}}$, Renny T. Franceschi ${ }^{\mathrm{b}}$, Michael D. Morris ${ }^{\text {a }}$

${ }^{a}$ Department of Chemistry and ${ }^{\mathrm{b}} \mathrm{S}$ chool of Dentistry, University of Michigan, Ann Arbor, Mich., USA

\section{Role of PLAA in $1 \alpha, 25(\mathrm{OH})_{2} \mathrm{D}_{3}$-Induced Rapid Membrane Response in both Chondrocytes and Osteoblasts}

M. Doroudi, Y. Wang, B.D. Boyan, Z. Schwartz

Georgia Institute of Technology, Atlanta, Ga., USA

\section{Application of Coherent X-Ray Diffraction Microscopy} in Biomineralization of Fish Bone

Huaidong Jiang a, b , Hong Liu a , Damien Ramunno-Johnson b, Changyong Song ', Yoshinori Nishino', Tetsuya Ishikawac, Jianwei Miao ${ }^{b}$

aState Key Laboratory of Crystal Materials, Shandong University,

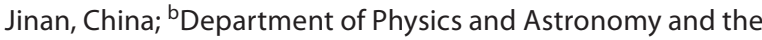
California NanoSystems Institute, University of California, Los Angeles, Calif., USA; 'RIKEN SPring-8 Center, Sayo, Japan

\section{The Role of Osteocalcin in the Toxic Effect of Lead on Bone Properties}

O. Berezovska ${ }^{a}, W^{\text {B Budell }}{ }^{\mathrm{a}}$, C.M. Gundberg ${ }^{\mathrm{b}}$, A. Ul Monir ${ }^{\mathrm{a}}$, M.C.H. van der Meulen ${ }^{\text {c, }}{ }^{\text {, A.L. Boskey }}{ }^{\text {d }}$, T.L. Dowd ${ }^{a}$

${ }^{a}$ Department of Chemistry, Brooklyn College of the City University of New York, Brooklyn, N.Y., b Department of Orthopedics, Yale University School of Medicine, New Haven, Conn., 'Sibley School of Mechanical and Aerospace Engineering, Cornell University, Ithaca, N.Y., and dHospital for Special Surgery, New York, N.Y., USA
Estrogen Regulation of PRG4 Expression in the Baboon Temporomandibular Joint

Jennifer S. McDaniel, Richard G. LeBaron

Department of Biology, University of Texas at San Antonio, San Antonio, Tex., USA

Fluoride Up-Regulated Amelogenin Expression in A/J Mice

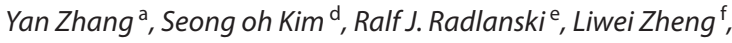
Ji Yeon Kim a , Sunita Ho ${ }^{b}$, Eric T. Everett ${ }^{c}$, Pamela K. Den Besten $^{\text {a }}$

${ }^{a}$ Department of Orofacial Sciences and ${ }^{b}$ Department of Preventive and Restorative Dental Sciences, University of California, San Francisco, Calif., and 'Department of Pediatric Dentistry, University of North Carolina at Chapel Hill, Chapel Hill, N.C., USA; dDepartment of Pediatric Dentistry, College of

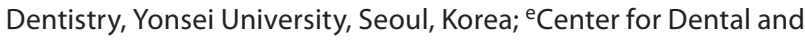
Craniofacial Sciences, Department of Craniofacial Developmental Biology, Charité - Campus Benjamin Franklin at Freie Universität

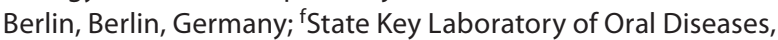
West China College of Stomatology, Sichuan University, Chengdu, China

\section{Chaperone Protein GRP-78 Is a Novel Player in} Biomineralization

Sriram Ravindran, Gao Qi, Asha Sarah Eapen, Amsaveni Ramachandran, Anne George

Brodie Tooth Development Genetics and Regenerative Medicine Research Laboratory, Department of Oral Biology, College of Dentistry, University of Illinois at Chicago, Chicago, Ill., USA

Unique Roles of DMP1 and Phosphate in Hard Tissues Afsaneh Rangiani ${ }^{\text {a }}$, Rong Zhang a , Omar Ashraf a ,Baozhi Yuan ${ }^{\text {, }}$ Yixia Xie a , Chunlin Qin a , Makoto Kuro-o $^{b}$, Jian Q. Feng ${ }^{\text {a }}$ aBiomedical Sciences, Baylor College of Dentistry, Texas A\&M Health Science Center and ${ }^{b}$ Pathology, University of Texas Southwestern Medical Center, Dallas, Tex., and 'Medicine, University of Wisconsin and GRECC, Madison, Wisc., USA

\section{A Marrow ‘Guardian' Cell Inhibits Marrow Space Mineralization and Trabecularization through Sost/ Sclerostin Expression}

$\underline{\text { X.Han }}{ }^{\text {a }}$, J. Gluhak-Heinrich ${ }^{\text {b }, Y . S u n ~}{ }^{\text {a }}$, T. Gao ${ }^{\text {a }}$, W. Yang ${ }^{\text {b }}$, MA. Harris ${ }^{\text {b }, ~ C . ~ Q i n ~}{ }^{\text {a , L.F. Bonewald }}$, , S.E. Harris ${ }^{\text {b }}$, Jian Q. Feng ${ }^{\text {a }}$ aBaylor College of Dentistry, Texas A\&M Health Science Center, Dallas, Tex., bDepartment of Periodontics, University of Texas Health Science Center at San Antonio, Tex., and 'School of Dentistry, University Missouri-Kansas City, Kansas City, Mo., USA 
Molecular Control of Enamelin and Kallikrein-4 Expression in Ameloblasts

Petros Papagerakis $^{\text {a, b }}{ }^{\text {, Maria Athanassiou }}{ }^{\text {a }}$, Lindsay Harbron ${ }^{\text {a }}$, Silvana Papagerakis c, Jim Simmer d, Jan Hu d

${ }^{a}$ Department of Orthodontics and Pediatric Dentistry, ${ }^{b}$ Center for Computational Medicine and Bioinformatics, 'Department of Otolaryngology and d Department of Biological Sciences and Materials, University of Michigan, Mich., USA

ALK3 Controls the Cell Fate of Tooth/Bone via TGF- $\beta$ Signaling Pathway

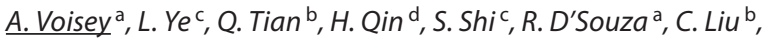
J. Feng a

${ }^{\mathrm{a} B}$ Baylor College of Dentistry, Dallas, Tex., ${ }^{\mathrm{b}} \mathrm{NYU}$ Hospital for Joint Diseases, New York, N.Y., 'UMKC, Kansas City, Mo., and 'USC Los Angeles, Calif., USA

Induced Folding of Recombinant Amelogenin in a Structure-Stabilizing Solvent; 2,2,2-Trifluoroethanol (TFE)

Moise Ndao a , Kaushik Dutta ${ }^{b}$, Keith M. Bromley ${ }^{c}$,

Rajamani Lakshminarayanan ', Zhi Sun ', Michael Goger b, Janet Moradian-Oldak ${ }^{c}$, John Spencer Evans ${ }^{\text {a }}$

aLaboratory for Chemical Physics, New York University and ${ }^{b}$ New York Structural Biology NMR Center, CUNY, New York, N.Y., and ${ }^{\mathrm{C} C e n t e r}$ for Craniofacial Biology, School of Dentistry, USC, Los Angeles, Calif., USA

Cloning and Structural Analysis of Lemur Amelogenin Rodrigo S. Lacruz ${ }^{\text {a }}$, R. Lakshminarayanan ${ }^{\text {d, Keith M. Bromley a, }}$ Timothy G. Bromage c, Joseph G. Hacia ${ }^{\text {b }}$, Malcolm Snead a, Janet Moradian-Oldak ${ }^{\mathrm{a}}$, Michael L. Paine ${ }^{\text {a }}$

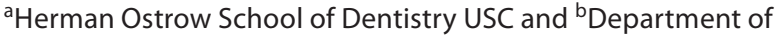
Biochemistry and Molecular Biology, USC, Los Angeles, Calif., and 'New York University College of Dentistry, New York, N.Y., USA;

${ }^{\mathrm{d}}$ Singapore Eye Research Institute, Singapore

Role of the $\mathrm{NH}_{2}$-Terminal Fragment of Dentin Sialophosphoprotein (DSPP) in Biomineralization Monica Prasad, Yao Sun, Xiaofang Wang, Qinglin Zhu, Jian Q. Feng, Chunlin Qin

Baylor College of Dentistry, Department of Biomedical Sciences, Dallas, Tex., USA

Self-Assembly of Amelogenin Oligomers: In-situ Atomic Force Microscopy and Dynamic Light Scattering Study

Chun-Long Chen ${ }^{\text {a }}$,Keith M. Bromley ${ }^{\mathrm{b}}$, Shibi Matthew ${ }^{\mathrm{b}}$, Janet Moradian-Oldak ${ }^{b}$, James J. DeYoreo ${ }^{a}$

a Molecular Foundry, Lawrence Berkeley National Laboratory, Berkeley, Calif., and ${ }^{b}$ Center for Craniofacial Molecular Biology, University of Southern California, Los Angeles, Calif., USA
Importance of Fibrillar Collagen for Regulation of Matrix-Protein Mediated Mineralization: A Study of Milk Osteopontin Fragments

Adele L.Boskey a , Hayat Taleb ${ }^{\text {a }}$, Esben S. Sørensen ${ }^{\text {b }}$

aMusculoskeletal Integrity Program, Hospital for Special Surgery, New York, N.Y., USA; ${ }^{b}$ Department of Molecular Biology,

Aarhus University, Aarhus, Denmark

Mouse Models to Investigate the Importance of Amelogenin Processing by MMP-20 during Enamel Development

M.K.Pugach ${ }^{\text {a }}$, C. Suggs ${ }^{\text {b }}$, J.D. Bartlett ${ }^{\text {c }}$, J.T. Wright ${ }^{\text {b }}$, A.B. Kulkarni ${ }^{\text {d }}$, C.W. Gibson ${ }^{\text {a }}$

aDepartment of Anatomy and Cell Biology, University of Pennsylvania School of Dental Medicine, Philadelphia, Pa., ${ }^{b}$ Department of Pediatric Dentistry, UNC School of Dentistry, Chapel Hill, N.C., 'Department of Cytokine Biology, Forsyth Institute, Boston, Mass., and 'Functional Genomics Section, Laboratory of Cell and Developmental Biology, NIDCR, NIH, Bethesda, Md., USA

On the Role Statherin and Analogue Peptides in the Biomineralisation Control of Enamel Homeostasis

Paul Anderson

Dental Physical Sciences Unit, Institute of Dentistry, School of Medicine and Dentistry, Queen Mary, University of London, London, UK

Knockdown of Osteopontin Alters Mineralization in Murine C3H10T1/2 Micromass Cultures

Rani Roy, Muang-Tin Kyaw, Valery Kudryashov, Adele Boskey Hospital for Special Surgery, New York, N.Y., USA

Ameloblastin in Enamel Formation: Rescue of Amelogenesis Imperfecta and Processing by Enamel Proteinases

Y.-H.P.Chun $^{\text {a }}$,Y. Yamakoshi ${ }^{\text {b }, ~ Y . ~ L u ~}{ }^{\text {b }, ~ Y . ~ H u ~}{ }^{\text {b }}$, F. Yamakoshi ${ }^{\text {b }}$, Y. Yamada ${ }^{\text {C, J.C.-C. Hu }}{ }^{\text {b }}$, J.P. Simmer ${ }^{\text {b }}$

aUniversity of Texas Health Science Center at San Antonio, San Antonio, Tex., bUniversity of Michigan, Ann Arbor, Mich., and 'National Institute of Dental and Craniofacial Research, Bethesda, Md., USA

Isolation of Uncleaved Porcine Dentin Sialophosphoprotein DSPP and Characterization of Its Processing

Yasuo Yamakoshi, Jan C.C. Hu, Fumiko Yamakoshi, James P. Simmer

Department of Biologic and Materials Sciences, School of Dentistry, University of Michigan, Ann Arbor, Mich., USA 


\section{A Unified Model of the Mechanisms of Initiation of} Calcification - the Roles of Phosphatases

José Luis Millán

Sanford Children's Health Research Center, Sanford-Burnham Medical Research Institute, La Jolla, Calif., USA

Dynamics of Amelogenin Self-Assembly during Its in vitro Proteolysis by MMP-20

Ruiwen Ma, Xiudong Yang, Sun Zhi, Keith Bromely, Daming Fan, Janet Moradian-Oldak

Center for Craniofacila Molecular Biology, Herman Ostrow School of Dentistry, Los Angeles, Calif., USA

Ab initio Simulations of Acidic and Phosphorylated Amino Acids to Study the Role of Phosphates in the Interaction of Osteopontin with Calcium Oxalate Monohydrate

Susanna Hug ${ }^{\text {a }}$ Harvey A. Goldberg ${ }^{\text {b }}$, Graeme K. Hunter ${ }^{\text {, }}$, Mikko Karttunen ${ }^{\text {a }}$

a Department of Applied Mathematics and ${ }^{\mathrm{b}}$ Department of Biochemistry, University of Western Ontario, London, Ont., Canada

Critical Features of Bone Sialoprotein in the Mediation of Hydroxyapatite Formation

Harvey A. Goldberg ${ }^{\text {a }}$, Gurprett S. Baht ${ }^{\text {, }}$ Jason O'Young ${ }^{\text {, }}$ Susanna Hug a , Mikko Karttunen ${ }^{b}$, Graeme K. Hunter ${ }^{\text {a }}$

aschool of Dentistry and Department of Biochemistry and

${ }^{b}$ Department of Applied Mathematics, The University of Western Ontario, London, Ont., Canada

New Methods for the Analysis of Protein Adsorption to in vitro Grown Calcium Pyrophosphate Dihydrate Crystals

Jason O'Young ${ }^{a}$, Yinyin Liao a, Bernd Grohe ${ }^{a}$, Mikko Karttunen ${ }^{\text {b }}$, Harvey A. Goldberg ${ }^{\text {a }}$ Graeme K. Hunter ${ }^{\text {a }}$

aSchool of Dentistry and bepartment of Applied Mathematics, University of Western Ontario, London, Ont., Canada

Influence of Different Crystallographic Orientations of Apatite Plates on Fibroblast Behavior

Marzena Suder ${ }^{a}$, Małgorzata Tyszka-Czochara ${ }^{b}$, Katarzyna Stadnicka ${ }^{\text {a }}$

a Faculty of Chemistry, Jagiellonian University, and ${ }^{\text {b}}$ Faculty of Pharmacy, Jagiellonian University Medical College, Krakow, Poland
The Role of Prion Protein in Dentinogenesis

Jean-Baptiste Souron a , Mayssam Khaddam a, Yan Zhang c, Dominique Ledenmat ${ }^{\mathrm{b}}$, Catherine Chaussain ${ }^{\mathrm{a}}$,

Pamela DenBesten ${ }^{c}$, Sibylle Vital ${ }^{\text {a, c }}$

aEA2496, UFR Odontology and baboratory of Radiology, Imaging and Biophysics, University Paris Descartes, Paris, France; 'Department of Orofacial Sciences, University of California, San Francisco, Calif., USA

\section{In vitro Formation of Carbonated Apatite from} Polyphosphate

Sidney Omelon a, Chrystia Wynnyckyj b, c, Marc Grynpas b, d ${ }^{a}$ Chemical and Biological Engineering, University of Ottawa, Ottawa, Ont., and bSamuel Lunenfeld Research Institute of Mount Sinai Hospital, 'Materials Science and Engineering, University of Toronto, and dLaboratory Medicine and Pathobiology Department, University of Toronto, Toronto, Ont., Canada

Influence of Composition, Amino Acid Sequence and Post-Translational Modification on Functional Role of SIBLING Proteins in Biomineralization

Atul Suresh Deshpande, Charles Sfeir, Elia Beniash

Center for Craniofacial Regeneration, Department of Oral Biology, University of Pittsburgh School of Dental Medicine, Pittsburgh, Pa., USA

\section{Initial Stages of Calcium Phosphate Nucleation on} Collagen

Jinhui Tao ${ }^{a}$, George Nancollas ${ }^{b}, J_{i m}$ De Yoreo ${ }^{a}$

aMolecular Foundry, Lawrence Berkeley National Laboratory, Berkeley, Calif., and bepartment of Chemistry, University at Buffalo, Buffalo, N.Y., USA

Identification of Amelotin (AMTN) and APin (ODAM)-Interacting Enamel Matrix Proteins Using the Yeast-Two Hybrid System

James Holcroft, Bernhard Ganss

Group in Matrix Dynamics, Faculty of Dentistry, University of Toronto, Toronto, Ont., Canada

Loss of Amelotin Results in Enamel Attrition due to Enamel Hypomineralization and Structural Defects

Yohei Nakayama, James Holcroft, Bernhard Ganss

Group in Matrix Dynamics, Faculty of Dentistry, University of Toronto, Toronto, Ont., Canada 
Dissecting Amelogenin Nanospheres Analysis of the Stable Oligomeric Forms

Janet Moradian-Oldak, Keith M. Bromley, Andrew Kiss, Daming Fan, Shibi Matthew, Rajamani Lakshminarayanan Center for Craniofacial Molecular Biology, University of Southern California, Los Angeles, Calif., USA

A Multi-Disciplined Approach to Characterize the Structure of the Murine Amelogenin Splice-Variant LRAP (Leucine-Rich Amelogenin Protein) in Solution and on Mineral Surfaces

Garry W. Buchko a , Barbara J. Tarasevich a , Ursula Perez-Salas ${ }^{\text {b }}$ Susan Krueger c, Charles F. Majkrzakc, David L. Masica ${ }^{\text {d, }}$ Jeffrey J. Gray ${ }^{d}$, Wendy J. Shaw ${ }^{\text {a }}$

aPacific Northwest National Laboratory, Richland, Wash., ${ }^{b}$ Argonne National Laboratory, Argonne, III., 'National Institute of Standards and Technology, Gaithersburg, Md., and ${ }^{d}$ John Hopkins University, Baltimore, Md., USA

Models for Amorphous Calcium Carbonate Based on Density Functional Calculations of Distortions Induced by Magnesium and Water in Calcite

S. Sinha ${ }^{\text {a }}$, M.P. Kocher ${ }^{\text {b }}$, D. Greenberg ${ }^{\text {a }}, \underline{\text { P. Rez }}^{\text {a }}$

${ }^{a}$ Department of Physics, Arizona State University, Tempe, Ariz., and 'bawrence Berkeley Laboratory, Berkeley, Calif., USA

Dynamics of Calcium Carbonate Polymorph during Larval Development and Metamorphosis in Marine Invertebrates: Effects of Ocean Acidification

Vera B.S.Chan a , Yanchun Wang ${ }^{\mathrm{b}}$, Yue He ${ }^{\mathrm{b}}$, Yuanqing Chao ${ }^{\mathrm{b}}$, Kaimin Shih ${ }^{\mathrm{b}}$, Tong Zhang ${ }^{\mathrm{b}}$, Vengatesen Thiyagarajan ${ }^{\mathrm{a}}$

aschool of Biological Sciences and bepartment of Civil

Engineering, The University of Hong Kong, Pokfulam, Hong Kong, China

Hydroxyapatite Growth Inhibition by Osteopontin Hexapeptide Sequences

L.D. Silverman, M. Saadia, J.S. Ishal, N. Tishbi, E. Leiderman, I. Kuyunov, B. Recca, C. Reitblat, R. Viswanathan

Department of Chemistry, Yeshiva University, New York, N.Y., USA

The Effects of Inhibitor Gradients on the Formation of Mineral in a Hydrogel-Based Double Diffusion System Jason R. Dorvee ${ }^{\mathrm{a}}$, Adele L. Boskey ${ }^{\mathrm{b}}$, Lara A. Estroffa

${ }^{a}$ Department of Material Science and Engineering, Cornell University, and ${ }^{\mathrm{b}}$ Weill Medical College, Cornell University and The Hospital for Special Surgery, New York, N.Y., USA
Reduced Bone Matrix Heterogeneity with Bisphosphonate Treatment in Women with Femoral Fractures

Eve Donnelly, Adele L. Boskey

Hospital for Special Surgery, New York, N.Y., USA

Scaffold-Less 3D Tissue Engineering: Development of a Spatially Organized Dentin-Pulp Complex

Fatima N. Syed-Picard ${ }^{\mathrm{a}, \mathrm{b}}$, Raymond S.K. Lam ${ }^{\mathrm{a}, \mathrm{c}}$, Gaurav Shah ${ }^{\mathrm{a}}$, Neil A. Robertson ${ }^{\mathrm{a}}$, Steven Cudney ${ }^{\mathrm{a}}$, Elia Beniash ${ }^{\mathrm{a}-\mathrm{c}}$, , Charles Sfeir $^{\mathrm{a}-\mathrm{c}}$ ${ }^{a}$ Center for Craniofacial Regeneration, ${ }^{b}$ Department of Bioengineering, and ${ }^{\mathrm{C}}$ Department of Oral Biology, University of Pittsburgh, Pittsburgh, Pa., USA

Effects of a Static Compressive Load Applied in vivo to the Proximal Tibial Physis in Rabbits

A. Bries ${ }^{\mathrm{a}}$, D. Weiner ${ }^{\mathrm{b}}$, R. Jacquet ${ }^{\mathrm{d}}$, M. Morscher ${ }^{\mathrm{b}}$, M. Adamczyk ${ }^{\mathrm{b}}$, R. Steiner ${ }^{c}$, M. Askew ${ }^{\text {a }}$, W. Horne ${ }^{d}$, E. Lowder ${ }^{\text {d }}$, W. Landis ${ }^{d}$

${ }^{\mathrm{a} S}$ Summa Health System, ${ }^{\mathrm{b}}$ Akron Children's Hospital and The University of Akron, Akron, Ohio, and d Northeastern Ohio Universities Colleges of Medicine and Pharmacy, Rootstown, Ohio, USA

Dental Alterations Associated with CamuatiEngelmann Disease

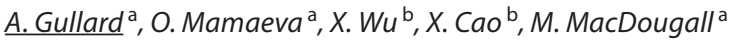
a University of Alabama at Birmingham School of Dentistry,

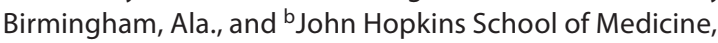
Baltimore, Md., USA

Ultrastructural Comparison of Bone-Like Nodules Formed from Mouse Embryonic Stem Cells, Mesenchymal Stem Cells and Primary Osteoblasts

$\underline{\text { S. Boonrungsiman }}^{\text {a, b }}$, E. Gentleman ${ }^{\text {a, b }}$, A.E. Porter ${ }^{\mathrm{a}}$, M.M. Stevens ${ }^{\mathrm{a}, \mathrm{b}}$

${ }^{\mathrm{a}}$ Department of Materials and ${ }^{\mathrm{b}}$ Institute of Biomedical Engineering, Imperial College, London, UK

Loss of Connexin 43 in Mature Osteoblasts and Osteocytes Results in Delayed Osteoblast Differentiation and Bone Remodeling during Fracture Healing

Alayna E. Loiselle, Andrew Billingsley, Emmanuel M. Paul, Yue Zhang, Henry J. Donahue

Department of Orthopaedics, Penn State College of Medicine, Hershey, Pa., USA 
Mesenchymal Stem Cells from Ossifying Fibroma

Haiyan Qin, Takayoshi Yamaza, Kentaro Akiyama, Anh D. Le, Songtao Shi

Center for Craniofacial Molecular Biology, School of Dentistry, University of Southern California, Los Angeles, Calif., USA

\section{Non-Classical Crystallization Mechanisms Involved} in Stone Formation?

Fairland F. Amos ${ }^{\text {a }}$, Saeed R. Khan ${ }^{\text {b }}$, Laurie B. Gower ${ }^{\mathrm{a}}$

${ }^{a}$ Department of Materials Science and Engineering and

${ }^{b}$ Department of Pathology, Center for the Study of Lithiasis,

University of Florida, Gainesville, Fla., USA

\section{3-D Cultures of Articular Chondrocytes in 1-D Diffusion Systems for Gradient Studies}

Deng (Debra) W. Lin ${ }^{a}$, Wangzhong Sheng a , Jason R. Dorvee a , Adele L. Boskey ${ }^{c}$, Lawrence Bonassar ${ }^{b}$, Lara A. Estroff ${ }^{a}$

a Materials Science and Engineering and ${ }^{\mathrm{b} B i o m e d i c a l ~ E n g i n e e r i n g, ~}$ Cornell University, Ithaca, N.Y., and ' Hospital for Special Surgery, Mineralized Tissue Research, New York, N.Y., USA

Transcriptional Regulation of Bone Sialoprotein Gene by Porphyromonas Gingivalis Lipopolysaccharide

Yorimasa Ogata $^{\text {a, b }}$, Zhengyang Li ${ }^{\text {a, c }}$, Li Yang a, c, Zhitao Wang a, c, Hideki Takai ${ }^{\mathrm{a}, \mathrm{b}}$, Xinyue $L i^{\mathrm{a}, \mathrm{c}}$

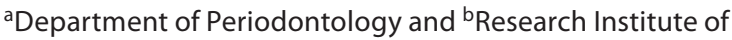
Oral Science, Nihon University School of Dentistry at Matsudo, Matsudo, Japan; 'Tianjin Stomatology Hospital, Tianjin, China

Nanoscale Morphology of Type I Collagen Is Altered in the Brtl Mouse Model of Osteogenesis Imperfecta

Joseph M. Wallace a , Bradford G. Orr b, Joan C. Marini ${ }^{\mathrm{c}}$, Mark M. Banaszak Holl a, b

Departments of a Chemistry and bPysics, University of Michigan, Ann Arbor, Mich., and 'Bone and Extracellular Matrix Branch, NICHD, NIH, Bethesda, Md., USA

\section{Three-Dimensional Osteoid Biomimetic Scaffolds Enhance Osteogenic Matrix Production and Mineralization}

Colin Welter ${ }^{a}$, Caroline Androjna ${ }^{a}$, Demin Wen ${ }^{a}$, Stacey Woo ${ }^{\text {, }}$ Lynda Bonewald $^{\mathrm{b}}$, Ronald J. Midura ${ }^{\mathrm{a}}$

aDepartment of Biomedical Engineering, Cleveland Clinic, Cleveland, Ohio, and ${ }^{b}$ Department of Oral Biology, School of Dentistry, University of Missouri at Kansas City, Kansas City, Mo., USA
Role of MEPE-Derived ASARM Peptide in Impaired Dentin Mineralization Associated with X-Linked Hypophosphatemic Rickets

B. Salmon ${ }^{\mathrm{a}, \mathrm{b}}$, C. Bardet ${ }^{\mathrm{a}}$, C. Willig a , A. Poliard ${ }^{\mathrm{a}}$, P. Rowe ,

C. Gaucher ${ }^{\mathrm{a}, \mathrm{b}}$, C. Chaussain $\mathrm{a}, \mathrm{b}$

${ }^{a} E A$ 2496, UFR d'Odontologie, University Paris Descartes, and ${ }^{b}$ Bretonneau Hospital, AP-HP, Paris, France; 'Kidney Institute University of Kansas Medical Center, Kansas City, Mo., USA

Comparison of the fro/fro and oim/oim Mouse Models of Osteogenesis Imperfecta Using FTIRI

Rhima Coleman ${ }^{\mathrm{a}}$, Christophe Poirier ${ }^{\mathrm{b}}$, Adele Boskey ${ }^{\mathrm{a}}$

aHospital for Special Surgery, Cornell University-Weill Medical College, New York, N.Y., and bepartment of Medicine, Vascular Biology Center, Medical College of Georgia, Augusta, Ga., USA

Osteogenic Differentiation of Human Bone Marrow Stromal Cells following $\mathbf{M g}^{\mathbf{2 +}}$ Ion Stimulation

Sayuri Yoshizawa, Andrew Brown, Charles Sfeir

Center for Craniofacial Regeneration, Department of Oral Biology, School of Dental Medicine, University of Pittsburgh, Pittsburgh, Pa., USA

Soluble Overexpression and Biophysical Characterization of Human Odontogenic AmeloblastAssociated Molecule in Escherichia coli

Olga Mamaeva a, Jennifer Ames ${ }^{a}$, James S. Foster ${ }^{b}$, Daniel P. Kestler ${ }^{\mathrm{b}}$, Mary MacDougall ${ }^{\mathrm{a}}$, Heidi Erlandsen ${ }^{\mathrm{a}}$ aschool of Dentistry, University of Alabama at Birmingham,

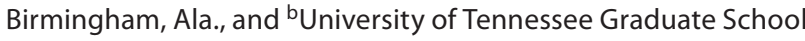
of Medicine, Knoxville, Tenn., USA

Stress-Induced Changes of Collagen Orientation in Tendon by Polarized Raman Spectroscopy

Admir Mašić ${ }^{a}$, Luca Bertinetti ${ }^{\text {a }}$ John W.C. Dunlop ${ }^{\text {a }}$, Jong Seto ${ }^{\text {a }}$ Markus A. Hartmann ${ }^{\text {b }}$, Peter Fratzl ${ }^{\mathrm{a}}$

${ }^{a}$ Department of Biomaterials, Max Planck Institute of Colloids

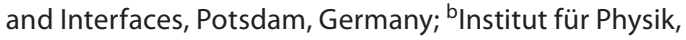
Montanuniversität Leoben, Leoben, Austria

\section{In vitro Self-Assembly of Human Amelogenin at} Oil-Water Interface

Olga Martinez-Avila ${ }^{a}$, Shenping Wu ${ }^{\mathrm{b}}$, Yifan Cheng ${ }^{\mathrm{b}}$, Xiaodong He ${ }^{\mathrm{a}}$, Stefan Habelitz ${ }^{\text {a }}$

aDepartment of Preventive and Restorative Dental Sciences, School of Dentistry, and bepartment of Biochemistry and Biophysics, University of California, San Francisco, Calif., USA 
Tethers Are Tightly Linked to Growth Plate and Synchondrosis Morphologies in Aged and VDR-Null Mice

Christopher S.D. Lee ${ }^{\text {a }}$, Jida Chen a, c, Yun Wang ${ }^{\text {, }}$ Joseph K. Williams ${ }^{b}$, Don M. Ranly ${ }^{a}$, Zvi Schwartz ${ }^{a}$, Barbara D. Boyan ${ }^{\text {a }}$

aWallace H. Coulter Department of Biomedical Engineering and Institute for Bioengineering and Bioscience, Georgia Institute of Technology, and ${ }^{b}$ Children's Healthcare of Atlanta, Atlanta, Ga., USA; ${ }^{C}$ Chongqing University, Chongqing, China

\section{Noggin Inhibition Increases Osteoblast Maturation on Titanium Microstructured Surfaces}

Sharon Hyzy ${ }^{a}$, Rene Olivares-Navarrete ${ }^{\text {a }}$, Qingfen Pan ${ }^{\text {a }}$, Ginger Dunn a , Michel M. Dard ${ }^{\mathrm{b}}$, Barbara D. Boyan ${ }^{\text {a }}$, Zvi Schwartz ${ }^{\mathrm{a}}$ aDepartment of Biomedical Engineering, Georgia Institute of

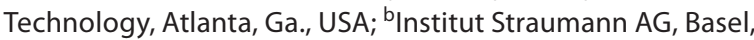
Switzerland

Surface Properties Direct Osteogenic Differentiation of Human Mesenchymal Stem Cells

Rene Olivares-Navarrete ${ }^{a}$, Sharon Hyzy ${ }^{\text {a }}$, Michel M. Dard ${ }^{\text {b }}$, Zvi Schwartza ${ }^{a}$ Barbara D. Boyan ${ }^{\text {a }}$

anstitute of Bioengineering and Bioscience, Georgia Institute

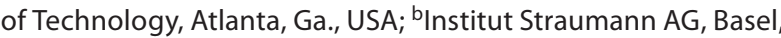
Switzerland

Effects of Soluble Factors from Pseudowollastonite $\left(\right.$ Beta-CaSiO $\left.{ }_{3}\right)$ Dissolution on in vitro Activity of Human Mesenchymal Stem Cells

Nianli Zhang ${ }^{\text {a }}$, Jim Molenda ${ }^{\text {b }}$, William Murphy ${ }^{\text {a-d }}$, John Fournelle e, Nita Sahai ${ }^{\text {a, e }}$

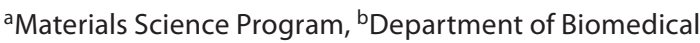
Engineering, and Departments of ${ }^{\mathrm{C} O r t h o p e d i c s}$ and Rehabilitation, ${ }^{\mathrm{d} P h a r m a c o l o g y}$ and ${ }^{\mathrm{e}} \mathrm{Geoscience,} \mathrm{University} \mathrm{of}$ Wisconsin, Madison, Wisc., USA
Tailorable Two-Level 3-Dimensional Interconnected Networked Bone Tissue Engineering Scaffold Constructed through an in vitro Biomineralization Method and Its Biocompatibility

Hong Liu ${ }^{a}$, Hongshi Zhao a , Guancong Wang a , Junying Miao ${ }^{\text {, }}$ Jiyang Wang a

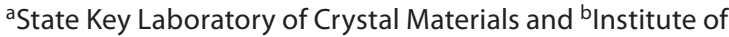
Developmental Biology, School of Life Science, Shandong University, Jinan, China

\section{Patient-Specific Hierarchical Simulation of Proximal} Femur

Maria-Grazia Ascenzi a, Joyce H Keyak ${ }^{\text {b }}$

${ }^{a}$ Orthopaedic Hospital/UCLA Department of Orthopaedic Surgery, University of California at Los Angeles, Los Angeles,

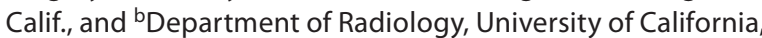
Irvine, Calif., USA

\section{The Developmental Clock of Enamel Formation}

Li Zheng ${ }^{a}$, Lindsay Harbron a, Santiago Schnell ${ }^{\text {b, d }}$, Silvana Papagerakis c, Petros Papagerakis a, d

Departments of a Orthodontics and Pediatric Dentistry, bPhysiology and ${ }^{\mathrm{C} O t o l a r y n g o l o g y}$, and ${ }^{\mathrm{d} C e n t e r ~ f o r ~ C o m p u t a t i o n a l ~}$ Medicine and Bioinformatics, University of Michigan, Ann Arbor, Mich., USA 